\title{
La evocación de la infancia en la poesía de César Dávila Andrade y Aurelio Arturo: entre la desmesura del espacio y la presencia gratificante de la naturaleza
}

\author{
The evocation of childhood in the poetry of César Dávila Andrade \\ and Aurelio Arturo: between the excess of space and the gratifying \\ presence of nature \\ Vicente Robalino* \\ Pontificia Universidad Católica del Ecuador \\ VROBALINO@puce.edu.ec
}

https://doi.org/10.32719/13900102.2018.43.3

Fecha de recepción: 19 marzo 2018

Fecha de aceptación: 18 mayo 2018

\section{RESUMEN}

En este ensayo se relacionan las posibilidades simbólico-evocadoras que tiene la naturaleza en la poesía del ecuatoriano César Dávila Andrade y el colombiano Aurelio Arturo, ante la desmesura del espacio que surge entre el presente de la evocación y el mundo evocado. Así como también la interiorización sensual y emotiva de la naturaleza en el yo lírico. De esta manera la evocación de la naturaleza fija y hasta petrifica el recuerdo, lo eterniza y evita su evanescencia del mundo evocado. En los dos poetas se puede apreciar una transfiguración simbólica de la naturaleza para evocar el mundo de la infancia y la intimidad familiar. En los dos autores es esencial la presencia de la madre, unida al paisaje rural cotidiano.

PALABRAS CLAVE: Ecuador, Colombia, César Dávila Andrade, Aurelio Arturo, poesía, memoria, evocación, olvido, infancia, madre, naturaleza, evanescencia, eternidad.

Ecuatoriano. Estudió Derecho en la Universidad Central del Ecuador. Doctor en letras por la Pontificia Universidad Católica de Quito. Obtuvo su Maestría y su doctorado en literatura iberoamericana en la UNAM, México. Profesor principal de la Escuela de Lenguaje y Literatura de la PUCE. Ha colaborado con revistas como Eskeletra de Quito y la de la PUCE. Autor de los poemarios: Póngase de una vez en desacuerdo (1990), Sobre la hierba el día (2001), Cuando el 


\section{ABSTRACT}

In this essay the symbolic-evocative possibilities that nature has in the poetry of the Ecuadorian César Dávila Andrade and the Colombian Aurelio Arturo are related to the excess of space that arises between the present of the evocation and the evoked world. It also relates the sensual and emotional interiorization of nature in the lyric self. In this way the evocation of nature fixes and even petrifies memory, perpetuating it and avoiding its evanescence from the evoked world. In the two poets one can see a symbolic transfiguration of nature to evoke the world of childhood and family intimacy. In both authors, the presence of the mother is essential, together with the daily rural landscape. KEY WORDS: Ecuador, Colombia, César Dávila Andrade, Aurelio Arturo, poetry, memory, evocation, forgetfulness, childhood, mother, nature, evanescence, eternity.

En la poesía de César Dávila Andrade y en la de Aurelio Arturo la naturaleza no es un mero pretexto, peor aún un decorado para desarrollar alguna escena bucólica; por el contrario, esta acorta la distancia entre el presente de la evocación y el mundo evocado. Como expresa Rafael Gutiérrez Girardot, al referirse a la poesía de Aurelio Arturo:

Esta concepción de la naturaleza, como lazo de continuidad histórica y como sustento de un alma 'común' americana, implica una expresión profunda de la 'poesía de la naturaleza', que sobrepasa los límites retóricos de la descriptiva apologética como la primera parte del Canto general (1950) de Pablo Neruda. Esa expresión es la de la 'emoción cotidiana', la del choque de la sensibilidad con la naturaleza $(2003,418)$.

En efecto, en los dos poetas, la evocación sienta sus raíces en la naturaleza, de manera especial en el agua y el sonido De tal manera que cuando esta no se encuentra presente en la evocación, el recuerdo, de manera especial en la poesía de Dávila Andrade, se vuelve evanescente, "se evapora". De ahí que la pregunta que intenta responder este trabajo es la siguiente: ¿¿de qué manera la naturaleza atenúa la distancia entre el presente de la evocación y el pasado evocado?

Por otra parte, como afirma Octavio Paz, "La creación poética se inicia como violencia sobre el lenguaje. El primer acto de esta operación consiste en el desarraigo de las palabras [... El segundo acto es el regreso de la palabra: el poema se convierte en objeto de participación." (Paz 1993, 38). La palabra de estos dos grandes autores latinoamericanos, César Dávila Andrade (Cuenca, 1918-Caracas, 1967) y Aurelio Arturo

cuerpo se desprende del alba (2007) y La invención del cielo (2008), El animal de la costumbre (2010), Para empezar el olvido (2013), Un animal parecido al deseo (Quito, 2017). En ensayo ha publicado: La reconstrucción del héroe liberal en la narrativa Sabatiana (2009) y Experiencias del exilio en Alejandra Pizarnik y César Dávila Andrade (2013). Consta en la antología Posta poética (1984), Antología del siglo XX (2009). 
(La Unión, Nariño-1906, Bogotá, 1974) sería doblemente desarraigada: como acto creativo y como experiencia de vida. En efecto, tanto Dávila Andrade como Aurelio Arturo, van a expresar, en una buena parte de su poesía, en un tono melancólico y hasta doloroso, el haber sido expulsados del paraíso de la infancia y de la adolescencia, aunque en el primero tal experiencia es mucho más acerba que en el segundo, pues Dávila Andrade se auto representa como un yo inmerso en una orfandad espiritual y humana inconmensurables; mientras que Aurelio Arturo puede evocar y hasta recorrer cada espacio, cada sonido, cada color, cada sabor donde transcurrió su infancia.

\section{La desmesura del espacio en César Dávila Andrade}

Entre el yo lírico que evoca y el objeto de la evocación se puede percibir, en la poesía de César Dávila Andrade, una distancia inconmensurable como en el poema "Carta de la ternura distante": "Estoy solo. La niñez vuelve a veces/con sus blancos cuadernos de ternura. / Oigo entonces el ruido del molino / y siento el peso de los días caer desde la torre de la iglesia/ con un sonido de aves de ceniza/" (Dávila 2007, 51). Lo que se reitera en este fragmento es la lejanía entre el yo que evoca y el objeto de la evocación, la inconstancia de la evocación y la explosión de esos días que se desploman, convertidos en cenizas.

Una de las consecuencias de la desmesura del espacio es el hecho de que el recuerdo se vuelve evanescente, como en el poema, "Canción para una muchacha de ojos verdes", cuando el autor expresa: "Vaporosa nodriza de una cuna de tréboles. / Ala de margarita que retoñan las hadas" (32). Toda la composición de este poema está encaminada a crear en el lector la sensación de la fugacidad de la evocación, sensación que se logra gracias al uso de imágenes impresionistas, como estas: "Arbolillos de leche tiemblan en tu retina/ junto a islas de verde sustancia evaporada" (32); "Tú, en el agua viajera, redonda como el mundo" (32); "Ligera como un ala de menta en las falanges" (32). Este poema-imagen no se resuelve en la certeza evocada, como en Aurelio Arturo, sino en la incertidumbre y en la inestabilidad del recuerdo, cuyo efecto final es la creación de una espacialidad sensual, dominada por la levedad aérea del espacio.

Otra de las formas de acrecentar la distancia entre el espacio de la evocación y los sujetos y objetos evocados es la creación de tiempos y espacios simultáneos, dentro de los cuales se vuelve imposible la distinción alguna ni entre sujetos ni entre tiempos y espacios, pues todo fluye como en una centrífuga. Así se puede apreciar en el poema "Infancia Muerta”, 
como en el siguiente fragmento: "Aquellas alas, dentro de aquellos días / aquel futuro en el que cumplí el Estío. Aquel pretérito en que seré un niño" (191). Esta inmersión en el pasado de la evocación, permite confundir deliberadamente los tiempos: presente, pasado y futuro o concebir, ilusoriamente, un presente y un futuro de ese pasado. Lo mismo sucede con los sujetos. Por ejemplo la madre, sus hijos y la nodriza, inmersos en situaciones asociativas metonímicas no solo inusuales sino absurdas: "La madre era ascendida al plenilunio encinta, / y en un suceso cóncavo, trasladaba sus hijos a sus nombres / y los dejaba atados a los postes de los campos" (191). Asociaciones estas meramente emotivas. Bien se podría pensar que son de carácter onírico, igual que las siguientes: "Arrimada a su paño de llorar, / venía la Nodriza, / tan humilde que no tenía derredor ni en Dios / Yo le besé en la piel los labios más profundos / de su cuerpo y desperté en el fondo de su vientre, al Niño sucesivo que no muere" (191). Así, el cuerpo de la evocación que en otros poemas poseen "la certidumbre de lo evanescente" -valga el oxímoron- en este, dicho cuerpo se disemina para adquirir -como en el surrealismo- las más insólitas asociaciones.

\section{"Carta a la Madre" o la intimidad familiar evocadora, el viento, el río y el árbol}

Si bien la evocación en este poema se centra en la madre inmersa en el espacio del hogar, la naturaleza proporciona, por una parte, un ambiente de ensoñación: "Y pensar que yo nunca sentí tu hambre, / que te robé un árbol azul y dos arbustos blancos" (79); por otra, causa un sufrimiento a la madre no exento de ternura, sufrimiento, presentido por el hijo desde el presente de la evocación: "No sufras porque el sábado amanezca con lluvia / ni porque el río baje con un ramo de lirios/" (79). Como afirma Gasón Bachelard: "El agua evoca en primer lugar la desnudez natural, la desnudez que puede guardar una inocencia" $(1993,59)$. Precisamente en este poema de Dávila Andrade, el río representa el reencuentro del niño con la madre pero en la eternidad, pues el lirio que arrastra el río es un elemento premonitorio de muerte. Así, como expresa Carlos Huamán, al estudiar los símbolos en la narrativa de Arguedas, el lirio está unido a la vida y a la muerte: "Se acepta el lirio como símbolo de la muerte, pero también como continuación de la vida en tanto que la muerte es transitoria" $(2004,258)$. A pesar de que la lluvia en la tradición occidental tiene un carácter fecundador: "La imagen de la lluvia en las mitologías de muchos pueblos representa la penetración en la tierra situada debajo de poderes celestiales y fertilizadores que descienden y señalan el matrimonio 
sagrado del cielo con la tierra" (Martin 2011, 62). En este poema de Dávila Andrade la lluvia enfatiza la premonición de muerte.

Mientras en los poemas anteriormente comentados, la evocación del yo lírico se difumina, debido a la distancia que media entre este y lo evocado, en "Carta a la Madre", dicha distancia, la del ahora ("Ahora que estoy tan lejos,"...) se atenúa e incluso se vuelve soportable para el yo lírico, porque la configuración poética de la carta permite que la intimidad familiar (madre e hijo) fluya y cree y mantenga latente la expectativa del recuerdo en el sujeto evocador. Dicha intimidad está formada por la vida cotidiana de la madre: "No madrugues a misa ni cojas el sereno". "No sufras porque ha muerto esa gallina blanca" (Dávila 2007, 79). El mundo de la madre es rural-andino, circundado de modestia y pobreza; muy cercano al que evoca César Vallejo y distinto al de Aurelio Arturo, pues en este autor se puede observar la presencia de la casa señorial: "la casa grande entre sus frescos ramos / En sus rincones ángeles de sombra y de secreto" (37). La intimidad familiar también se expresa, en este poema, por medio de la confesión que hace el hijo a su madre -dentro de la intimidad familiar- el hecho de estar enamorado de su prima, quien el momento de contestar la carta a su madre, ha fallecido: "Ya recibí tu carta. ¡Escrita con romero y pestañas azules! / Me cuentas que se ha muerto mi prima María Augusta. / Ahora que estoy lejos, te diré: Yo la amaba" (79). A esta confesión se une un pedido: "Baja mañana a verla con un ramo de nardos, / y recítale alguna oración impalpable” (79), una nueva revelación, que se encuentra relacionada con la biografía del autor, el alcoholismo crónico del que padecía César Dávila Andrade: "Dile que ya no bebo y que he pasado el año" (79). Al respecto, Jorge Dávila Vásquez, afirma:

Pero aquí estamos, una vez más, ante la capacidad transformadora del poeta: la condición deplorable del ebrio que abandona el oscuro cuchitril donde ha bebido [...], se transforma en un estado de gracia, como si ocurriera ante nosotros una revelación, una epifanía daviliana, $[\ldots]$. En efecto, parece que Dávila sintiera la embriaguez como uno de esos estados que marcó su vida entera $(1998,96)$.

La reiteración final del protagonista poemático, del amor a su madre, transfigurado en el amor hacia una mujer: "Y ahora, yo quisiera decirte que te amo, / pero de una manera que tú no sospechaste./Verás. Ahora te amo en todas las mujeres, / te amo en todas las mujeres, /te amo en todas las madres, te amo en todas las lágrimas" (Dávila, 2007, 80). Así hemos visto cómo solo la intimidad familiar es capaz de borrar la distancia que media entre el tiempo espacio de la enunciación y el tiempo-espacio del enunciado. 
Pero ¿̨cómo era la relación familiar de Dávila Andrade?, según Jorge Dávila Vásquez, tanto las relaciones familiares como las relaciones sociales de este autor están marcadas por la hostilidad. Así con su padre mantuvo discrepancias políticas y personales, que lo alejaron de él: "La relación de nuestro poeta con su padre, Rafael Dávila Córdova, era bastante difícil; fuera por razones de actitud vital y humana frente al mundo y la realidad, fuera por motivos de orden político, fuera, en fin, por un amor filial muy fuerte hacia la madre," [...] (Dávila Vázquez 1998, 41). Asimismo -de acuerdo con este mismo autor- Cuenca, la ciudad natal de Dávila Andrade, también le creó una actitud de rechazo: "En relación con su distanciamiento afectivo con Cuenca, este se debió seguramente a que la ciudad lo desconoció -y no solo en sus primeros años-, condenándolo a un anonimato grosero, a los trabajos más humildes y peor remunerados" (43).

\section{"Carta a una colegiala", la mediación de la naturaleza entre la evocación y lo evocado: el recuerdo de un olvido}

Dentro de esta misma línea de atenuación de la distancia, entre el acto de evocación y lo evocado, se encuentra el poema, "Carta a una colegiala". En él, aparte del motivo recurrente del amor, se puede reconocer a la naturaleza (a la topografía) como el espacio encargado de acortar la distancia entre el enunciador y enunciado, por el efecto amoroso $\mathrm{y}$, al mismo tiempo, dotarle de perdurabilidad al recuerdo, porque, en este poema, igual que en el anterior, es el género epistolar -la carta- la que permite al protagonista poemático confiar su intimidad amorosa; sin embargo, dicha intimidad no se queda en el ser amado, sino que atraviesa su corporeidad para situarse en el cuerpo estable e indestructible de la naturaleza: "Para leer esta carta / baja hasta nuestro río./ Escucharás, de pronto, una cosecha de aire/pasar sollozando en la corriente /" (Dávila 2007, 61). Tómese en cuenta que la condición para que la carta surta el efecto deseado -la comunión espiritual entre los amantes- es el hecho de que sea leída en presencia de la naturaleza, de la que los amantes se han apropiado, así lo expresa la frase: "nuestro río". Como afirma Gonzalo Ramón: "Así como en las poesías de Antonio Machado se nota la obsesión de la fuente y el jardín, el ciprés y el limonero; así a César le halagan el río y el agua" $(1968,7)$. En efecto, asimismo, el cuerpo de la amante-colegiala se encuentra impregnado de naturaleza: "Veo tu blusa de naranja ilesa. / Tus principiantes senos de azucena, / y siento que me duele la memoria" (61). Además, la naturaleza, en este poema es sinónimo de inocencia, de 
pureza. Cabe destacar cómo la ausencia del ser amado se convierte en el sujeto evocador en un dolor físico: "Siento que me duele la memoria". Dicha ausencia la registra el protagonista poemático, puntualmente, en meses y años: "Mañana son dos años, siete meses"; "Mañana entramos ya en el mes de junio" (61). Sin embargo, cabe señalar que el "dolor de la memoria" es causado por la distancia física en la que se encuentran los amantes: "Tú, en el divino campo. Yo, en la ciudad terrestre". Distancia que por ser insalvable produce mucho dolor en el enunciador del poema. Aparte de dicha distancia, el olvido actúa como un implacable roedor, encargado de acrecentar el "dolor de la memoria": "Pienso en la estatua de aire de tu olvido/ mirándome de todas las esquinas, mi colegiala mía, música femenina" (61). Entonces, si bien la evocación se transfigura en la naturaleza para darle a esta cierta permanencia en el tiempo y espacio, el olvido no es del recuerdo en sí, sino de la propia relación amorosa. De ahí que bien se podría hablar en este poema del "recuerdo de un olvido"

\section{"Canción a Teresita": entre lo evanescente y la perdurabilidad en el paisaje}

Es particularmente interesante en este poema, las distintas formas poéticas de lo etéreo-lo fugaz y evanescente- en las que es concebida, Teresita, la protagonista, quien es vista, tanto desde el olvido como desde la memoria del yo lírico. Ella es una construcción netamente espiritual. Esto hace que se mantenga incólume al olvido, por lo menos al olvido humano, ya que permanece en el éter. Pues varias son las asociaciones tropológicas de este personaje con el mundo espiritual. Así podemos verla como una especie de mártir, o santa, unida a la pasión de Cristo: "Pálida Teresita del Infante Jesús, / quién pudiera encontrarte en el trunco paisaje de las estalactitas, / o en esa nube que baja, de tarde, a los dinteles, / entre manzanas blancas, en una esfera azul./ [...] / Y hallar entre tus sienes mínimos crucifijos" (34). Esta primera imagen evocada de Teresita, que persiste en la mente del yo lírico, está unida al sufrimiento, dado por la enfermedad: "Cómo escucho en la noche de caídos termómetros, / volar, rotas las alas, el ave de tu tos; / y llorar en las islas de una desierta estrella / a jóvenes arcángeles enfermos como tú" (34). De esta manera se puede apreciar cómo la enfermedad de la protagonista de este poema posee también el carácter de etéreo. Además, a Teresita se la vincula con uno de los seres míticos que forman parte del aire, las sílfides: “allí estás tú, Teresita, víspera del rocío, / en la hornacina pura de un nevado corpiño, con tu fantasma tenue, concebido en la línea / ligera y sensitiva en que 
nacen las sílfides" (35). Finalmente, Teresita es proyectada hacia el espacio sideral, a través de resonancias polifónicas (como un coro celeste), que la evocan desde la aliteración: "Suave, sombra, celeste, / soledad silenciosa."; "Tenue, tímida, tibia, translúcida / turgente"; "Delgada, dulce, débil, / divina, delicada"; "Niña, nupcial, nerviosa, / nívea, naciente, núbil" (35); "Ideal, ilusa, íntima, / irreal, iluminada" (35). Cada uno de estos paralelismos aliterativos, si bien juegan con lo evanescente, la evocación intenta, no sé si vanamente, eternizarlas.

Sin embargo, Teresita, al mismo tiempo que es, como hemos visto, presencia evanescente, se convierte en sustancia pétrea fija en el espacio: "quién pudiera encontrarte en el trunco paisaje de las estalactitas / o en esa nube que baja, de tarde, a los dinteles" (34). En este sentido, el poema LXV de Trilce comparte esta misma transfiguración del sujeto en sustancia pétrea, pues la "muerta inmortal" es la madre, reconstruida por la memoria, como una fortaleza indestructible: "Entre la columnata de tus huesos/que no puede caer ni a lloros / y a cuyo lado ni el Destino pudo entrometer/ni un solo dedo suyo" (Vallejo 1988, 251).

\section{Aurelio Arturo: la evocación espiritual de la naturaleza}

Quizá el punto de convergencia entre la poética de César Dávila Andrade y Aurelio Arturo, con respecto al tema del viaje hacia la infancia y la adolescencia, sea el alto grado de sensibilidad con respecto a la aprehensión, en el recuerdo, de la naturaleza, como lo muestran los dos poetas. En efecto, tanto uno como otro, buscan despojar al paisaje de sus atavíos retóricos para convertirla en una vivencia íntima que, como tal, forma parte de la propia existencia. Así, Aurelio Arturo en su "Morada al Sur" nos invita a un viaje de constatación de la esencia de la naturaleza y de sus efectos en el ánimo, tanto del autor-creador como del lector. De esta manera podemos percibir el tránsito de la noche al día: "En las noches mestizas que subían de la hierba, / sombras curvas, brillantes, / estremecían la tierra con su casco de bronce. / Después, de entre grandes hojas, salía lento el mundo" (Arturo 2003, 35). Esta suerte de "resurrección" del tiempo desde la noche hacia el día, no solo es en este poema la constatación de un hecho natural sino el "testimonio poético" de una vivencia que habita en la intimidad del yo poético. Esta alternancia sol-sombra; claridad-oscuridad nos remite, especialmente, a la creación mítico-egipcia del dios sol y a las consecuencias de su ausencia en la noche: "Se llama a la génesis", "La primera vez" porque cada día constituye una nueva vez. La noche es la inmersión del sol envejecido en el oscuro 
océano primordial. Cada mañana le ve volver rejuvenecido, no sin que el astro haya combatido con las fuerzas rebeldes que se habían levantado desde los primeros tiempos del mundo" (Parain 1972, 16). Esta muerte nocturna y esta resurrección diurna configuran la poesía de "Morada Sur". Sin embargo, a diferencia del mito egipcio, la noche en Aurelio Arturo si bien es desconcierto, incertidumbre, miedo y muerte, tiene la virtud de despertar a una parte de la naturaleza: "Te hablo de un bosque extasiado que existe / solo para el oído, y que en el fondo de las noches pulsa/violas, arpas, laúdes y lluvias sempiternas" (38).

A medida que avanza el poema, se vuelve más evidente la luz. Entonces van apareciendo en la memoria del yo evocador estos personajes: un caballo, una vaca, un pájaro, el agua, el viento, un ave, la nodriza, hombres, las abejas, mujeres, las lunas... Pues una vez que el día se instala entre las montañas, estos personajes van haciendo su aparición, para construir escenas impresionistas, en las que las senso-percepciones, principalmente las del oído y la vista, se combinan libremente solo guiadas por la intuición evocadora del poeta. Así vemos a un caballo aún confundido entre las sombras nocturnas: "sombras curvas, brillantes," cuyos cascos "estremecían la tierra". A una vaca, sorprendida por la lente del poeta, mientras la luna cae oblicuamente sobre su cuerpo y lo revela, de la misma manera que se evidencia, por pausas, el canto del pájaro toche. Cuando el agua aparece en su transparencia, para transformarse en una imponente catarata, ya el día ha avanzado. No menos sensible es el paso del viento que se agita, sube y baja para, finalmente, detenerse "ante las puertas grandes", como quien indaga sobre la presencia humana. La aparición de la nodriza, entre este pausado deambular de seres de la naturaleza, representa la perfecta combinación de la sensualidad de la naturaleza: visual, auditiva y táctil, con el erotismo, es decir a la metaforización de lo instintivo, como llamaría Octavio Paz. Dicha combinación, así lo expresa Aurelio Arturo: "Yo miro las montañas. Sobre los largos muslos/de la nodriza, el sueño me alarga los cabellos" (36). De ahí que el acto de la evocación en este autor -como en algunos poemas de César Dávila Andrade- adquiera una completa plenitud y que surja como resultado del encuentro de dos espiritualidades: la de la naturaleza y la de la vivencia evocadora.

\section{Encuentros y desencuentros de la memoria}

Tanto en los poemas de César Dávila Andrade, comentados en este trabajo, como "Morada Sur", de Aurelio Arturo, la memoria está hecha de muchos olvidos o, precisamente, aquellos olvidos son los que permiten 
escarbar en el tortuoso camino del recuerdo. En este sentido me parece muy pertinente lo que expresa la crítica colombiana Beatriz Restrepo en relación con "Morada Sur": "Es cierto que la brújula marca hacia el sur. Pero no el del idilio, porque el viaje no será posible sin los destellos fugaces, profundos, del miedo y del espanto" (Restrepo 2003, 475). Desde luego que en este extenso poema de Arturo, el viento, por ejemplo, tiene una presencia fantasmal en aquellas "noches mestizas" infunde miedo, porque es el encargado de constatar, en el gran caserón las ausencias, el vacío, la muerte. Sin embargo, como hemos afirmado en este trabajo, el viaje que emprende Aurelio Arturo hacia sur no solo está circundado de olvidos, sino de hallazgos, sin que por ello tenga el carácter de "idílico". Si comparamos con la exploración del pasado que emprende César Dávila Andrade, en el cual si bien el recurrir a la naturaleza le proporciona a su recuerdo un leve alivio a su aguda "dolencia" del desarraigo y a la constante fragmentación del recuerdo que, finalmente, lo llevaría al suicidio, en un hotel de Caracas donde se cortaría la yugular con una hoja de afeitar, el 2 de mayo de 1967; mientras que Aurelio Arturo pensaría, desde Bogotá, desde donde, según Beatriz Restrepo "conquistaría poéticamente la ciudad, pues su mirada se orientaría hacia el norte", como afirma esta crítica, así: "Su poesía recreará el camino que hizo entre los campos de su infancia y la ciudad que lo acogió, que será igualmente el canto de la transformación de las sociedades agrícolas en urbanas" (475).

\section{Bibliografía}

Arturo, Aurelio. 2003. Obra poética. México: Fondo de Cultura Económica.

Bachelard, Gastón. 1993. El agua y los sueños. México: Fondo de Cultura Económica.

Dávila Andrade, César. 2007. Obra poética. Quito: Casa de la Cultura Ecuatoriana.

Dávila Vázquez, Jorge. 1998. César Dávila Andrade: Combate, poética y suicidio. Cuenca, Facultad de Filosofía, Letras y Ciencias de la Educación.

Ferrari. Américo., coord. 1988. César Vallejo. Obra poética. México: Fondo de Cultura Económica.

Gutiérrez Girardot. Rafael. 2003. "Historia y naturaleza en la poesía de Aurelio Arturo". En Aurelio Arturo Obra poética. México: Fondo de Cultura Económica. 
Huamán, Carlos.2004. Pachachaca. Puente sobre el mundo. Narrativa, memoria y simbolo en la obra de José María Arguedas. México: Centro Coordinador y Difusor de Estudios Latinoamericanos. UNAM.

Martin Kathleen. 2011. El libro de los símbolos. Reflexiones sobre las imágenes Arquetípicas, China. Taschen.

Moreno-Durán. Rafael, coord. 2003. Obra poética. Aurelio Arturo. México: Fondo de Cultura Económica.

Parain, Brice, coord. 1972. El pensamiento presocrático oriental. México: Siglo XXI.

Paz. Octavio. 1993. El Arco y la lira. México: Fondo de Cultura Económica.

Ramón, Gonzalo. 1968. Ensayos sobre César Dávila Andrade, Miguel Ángel Zambrano y notas sobre varios poetas ecuatorianos. Quito: Casa de la Cultura Ecuatoriana.

Restrepo, Beatriz. 2003. "Memorias y olvidos en Morada Sur" en Obra poética Aurelio Arturo. México, Fondo de Cultura Económica.

Vallejo, César. 1988. Obra poética. México: Fondo de Cultura Económica. 